\title{
ReSOR Di Tengah Kota Di SURAKARTA
}

\author{
Kartika Fitri Annisa, Agung Kumoro W, Suparno \\ Program Studi Arsitektur \\ Fakultas Teknik \\ Universitas Sebelas Maret Surakarta \\ Email : kfannisa93@gmail.com
}

\begin{abstract}
The design of Urban Resort motivated by the increasing number of tourists coming to the city of Solo as increasing tourism potential. The increasing number of tourist coming and tourist potential are not accompanied by an increase in the numbers LOS (Length Of Stay) and the availability of lodging facilities that accommodate in Solo. The purpose of this scheme is to get a building design that is able to accommodate the needs of lodging accommodations and recreation in the form of a resort hotel in the center of the city of Solo with the implementation of ecological architecture as a form of support to the Government to make Solo as an ecological city. Design issues are: how the concept of ecological architecture can be applied in the design of Urban Resort in Surakarta. The method used is the method of architectural design with mix of the theory about ecological architecture with Government Regulation about requirements of five star resort hotel. The results obtained are the design of urban resort as a means of lodging accommodations, and public space as a tourist attraction and people who apply the concept of ecology architecture on the shape and appearance of the building. So that the building can give the impression of a comfortable and natural even though the resort hotel located in the middle city of Solo.
\end{abstract}

Keywords: Architecture, Ecological Architecture, Urban Resort.

\section{PENDAHULUAN}

Kota Solo khususnya pada pemerintahan Joko Widodo telah mengembangkan perbaikan dan peningkatan pola dan tata ruang kota yang ekologis, contohnya Mega Proyek City Walk, penataan bantaran Kali Tirtonadi, dan Kali Anyar. Meskipun telah mampu membenahi tata ruang kota, namun ternyata RTH di Solo hanya mencapai 4,6\%. Maka dari itu pemerintah Kota Solo terus berusaha mengembangkan ruang terbuka hijau agar dapat mencapai 30\% dengan cara menata tata ruang kota dengan konsep kawasan yang ekologis.

Perkembangan pariwisata Kota Solo terus meningkat diiringi terus berkembangnya acara-acara budaya yang dilakukan di Kota Solo. Perkembangan pariwisata di Kota Solo tidak hanya meningkatnya acara-acara budaya namun diiringi dengan meningkatnya kualitas dan kuantitas pada wisata kuliner dan wisata belanja di Kota Solo. Seiring meningkatnya perkembangan pariwisata di Kota Solo, peningkatan jumlah wisatawan lokal maupun asing juga terus meningkat pesat.
Namun, fenomena tersebut tidak diiringi dengan meningkatnya jumlah angka LOS (Length of Stay) Kota Solo. Hal ini harusnya menjadi perhatian karena Kota Solo juga memiliki potensi pariwisata budaya yang dapat disandingkan dengan kota Yogyakarta yang angka LOSnya mencapai 2-3 hari dibandingkan dengan Kota Solo yang hanya mencapai 1,5 hari (SDA, 2012). Meninjau fenomena tersebut, salah satu langkah strategis adalah dengan membangun sarana rekreasi dan relaksasi yang memiliki nilai unik sehingga mampu menarik minat wisatawan untuk datang dan tinggal lebih lama di kota Solo. Untuk memperbesar peluang menarik wisatawan datang dan tinggal lebih lama di kota Solo, diperlukan sebuah hotel berkonsep hunian bernuansa rekreasi dan relaksasi yang selaras dengan konsep pengembangan kota Solo yang ekologis dengan memberikan daya tarik pariwisata di dalam hotel yang mampu melibatkan masyarakat umum, pemerintah maupun wisatawan.

Kebutuhan akan desain dengan konsep ekologis dan perwujudan desain akan sebuah wadah yang mampu mengembangkan 

pariwisata, dan pemenuhan kebutuhan fasilitas tempat tinggal berupa hotel dengan konsep yang berbeda menjadi landasan kuat untuk sebuah respon. Hal tersebut dapat diwujudkan di Kota Solo dalam bentuk Urban Resort dengan Pendekatan Ekologi Arsitektur.

Pada perancangan Urban Resort yang menjadi poin penting adalah penerapan ekologi arsitektur pada bangunan untuk mendapatkan sasana resor yang nyaman dan alami meskipun terletak di tengah kota. Prinsip ekologi arsitektur menjadi landasan dalam perancangan bentuk dan penataan masa serta respon bangunan terhadap iklim. Hal ini juga akan berpengaruh pada tampilan bangunan yang nantinya akan menggunakan materialmaterial alam untuk menonjolkan kesan alami.

\section{METODE}

Metode yang digunakan adalah penguraian aplikasi prinsip-prinsip Ekologi Arsitektur menjadi sebuah strategi desain dalam perancangan. (Frick, 1999) menjelaskan beberapa prinsip kriteria arah pembangunan ekologis sebagai berikut.

1. Menghemat energi dengan memanfaatkan energi terbarukan dan efisiensi penggunaan air.

2. Merancang bangunan yang sehat dengan menerapkan pencahayaan dan penghawaan alami yang maksimal.

3. Pembentukan bangunan dan penerapan tampilan mempertimbangkan dengan respon terhadap iklim.

Oleh karena itu, pada perancangan Resor di Tengah Kota, kriteria-kritera Ekologi Arsitektur di atas berperan pada:

1. Penentuan orientasi bangunan.

Orientasi bangunan adalah bentuk respon bangunan terhadap iklim. Bangunan sebaiknya menghindari arah barat dan timur untuk menghindari sinar matahari langsung, dan mengarah ke barat laut atau tenggara untuk memaksimalkan penghawaan alami.

2. Penataan massa bangunan dan tampilan.

Penataan massa bangunan dipengaruhi oleh respon bangunan terhadap iklim, dengan memberikan ruang terbuka dari arah barat laut dan tenggara agar angin dapat bergerak dengan mudah masuk ke dalam tiap-tiap bangunan.

3. Utilitas bangunan.

Utilitas pada bangunan harus menerapkan energi terbarukan dan pengolahan kembali limbah-limbah air yang dapat digunakan.

\section{ANALISIS}

A. Analisis Lokasi

Selain menentukan lokasi yang strategis, memilih tapak dengan kondisi yang mendukung keberadaan Urban Resort.

a. Tujuan

Mendapatkan lokasi yang sesuai dengan Urban Resort.

b. Dasar pertimbangan:

Berada di tengah kota, berada di daerah pengembangan pariwisata sesuai dengan RUTRK Solo, Kemudahan aksesbilitas dan pencapaian, serta ketersediaan lahan.

\section{B. Analisis Pencapaian}

Pencapaian ke dalam bangunan harus mudah diakses, mudah dilihat dan memiliki sirkulasi yang aman akan menstimulus orang untuk masuk dalam area bangunan.

1. Tujuan: menentukan main entrane, menentukan service entrance

2. Dasar Pertimbangan: kemudahan akses, sirkulasi tapak yang aksesibel, arus kendaraan dan potensi jalan, tingkat keamanan.

3. Proses analisis

Main Entrance (ME)

Mudah dijangkau dan terlihat dengan jelas. Menghadap langsung ke arah jalan untuk kemudahan sirkulasi kendaraan masuk dan ke luar tapak. Karena tapak terletak di antara dua persimpangan jalan, maka ME lebih baik diletakkan menjauhi persimpangan agar tidak menambah kemacetan (lihat Gambar 1).

Side Entrance (SE)

Digunakan untuk pengguna servis untuk jalannya operasional hotel resor. Terletak di bagian jalan yang 

tidak mengganggu pandangan pengguna hotel resor (lihat Gambar $1)$.

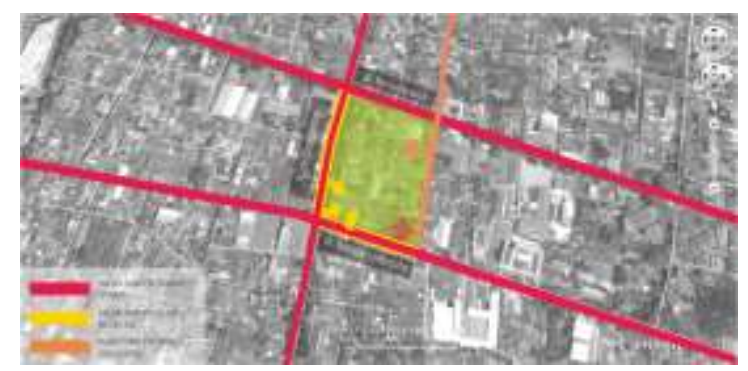

Gambar 1. Pola Pencapaian.

C. Analisis Respon Bangunan Terhadap Iklim

Respon bangunan terhadap iklim dipengaruhi oleh pergerakan matahari dan angin. Pada konsep ekologis, iklim menjadi dasar paling penting dalam menentukan bentuk dan tampilan bangunan.

1. Tujuan: Mendapatkan orientasi dan posisi bangunan agar bangunan dapat menyesuaikan diri terhadap iklim.

2. Dasar Pertimbangan: Memaksimalkan penghawaan alami dan mengurangi sedikit mungkin tampilan bangunan yang terkena sinar matahari langsung.

3. Proses analisis:

a. Angin: Bergerak dari arah barat laut menuju ke tenggara dan sebaliknya dari tenggara menuju barat laut. Maka dari itu, dalam penataan massa bangunan, hendaknya mengikuti arah-arah pergerakan angin.

Pembentukan massa banyak tentunya dapat menggerakan angin pada tapak lebih efisien. Bentuk bangunan sebaiknya juga di rancang tipis agar angin dapat dengan mudah keluar masuk massa bangunan.

b. Matahari: Tapak relatif mendapatkan sinar matahari sepanjang tahun. Khususnya dari sisi barat tapak. Untuk mengatasi hal tersebut, orientasi bangunan baiknya menjauhi orientasi timur dan barat untuk mengurangi sinar matahari langsung masuk ke dalam bangunan. Selain itu, untuk memberikan kenyamanan pada ruang-ruang dalam bangunan, pada bangunan yang terkena sinar matahari langsung dapat menggunakan sun shading untuk menghalangi sinar matahari langsung masuk ke dalam ruangan.

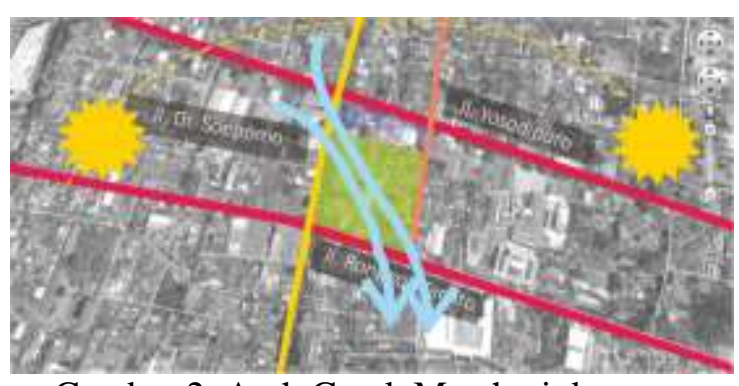

Gambar 2. Arah Gerak Matahari dan Angin Pada Tapak.

D. Analisis Pandangan (View)

1. Tujuan: Untuk menentukan posisi terbaik peletakan ruang yang menjadi daya tarik pengguna dan dapat memberikan kenyamanan visual.

2. Dasar pertimbangan: Pandangan sekitar tapak yang dapat memberikan kenyaman visual pada pengguna hotel resor.

3. Proses analisis: Dari arah selatan dan barat daya tapak, pandangan dari dalam tapak terdapat bangunan-bangunan perkantoran Jalan Slamet Riyadi yang sangat berpotensial dan beberapa obyek wisata yang sangat berpotensial. Dari arah barat terdapat bangunanbangunan ruko dan pemukiman penduduk yang kurang berpotensial. arah timur laut terdapat pemukiman penduduk yang cukup berpotensi, karena didukung dengan obyek wisata yang dapat dijadikan pandangan yang menarik dari dalam tapak, yaitu Keraton Mangkunegaran, 
dan Monumen Pers (lihat Gambar $3)$.

Maka dari itu, peletakan ruangruang yang membutuhkan pandangan diletakkan mengarah kea rah barat daya dan timur laut.

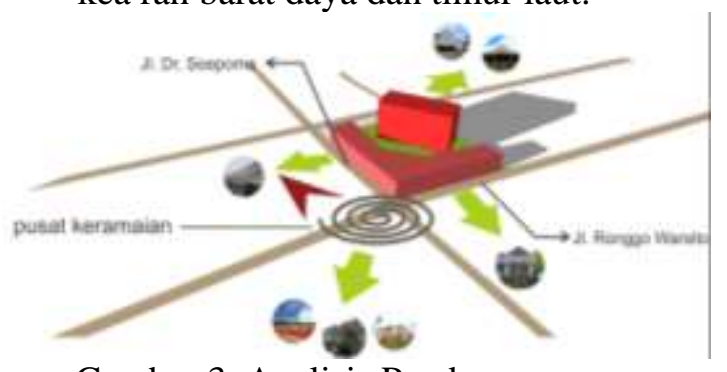

Gambar 3. Analisis Pandangan.

E. Analisis Orientasi Bangunan

1. Tujuan: Menentukan orientasi bangunan hotel resor.

2. Dasar pertimbangan: Respon orientasi bangunan terhadap iklim dan kesesuaian tapak dengan letak tapak terhadap jalan sekitar.

3. Proses analisis: Untuk dapat menciptakan ruang-ruang dalam hotel yang nyaman untuk penghuni, maka orientasi bangunan harus menghindari paparan sinar matahari secara langsung. Dalam hal ini, paparan sinar matahari Kota Solo dari arah barat dan timur. Maka dari itu, baiknya orientasi bangunan menghindari arah barat dan timur.

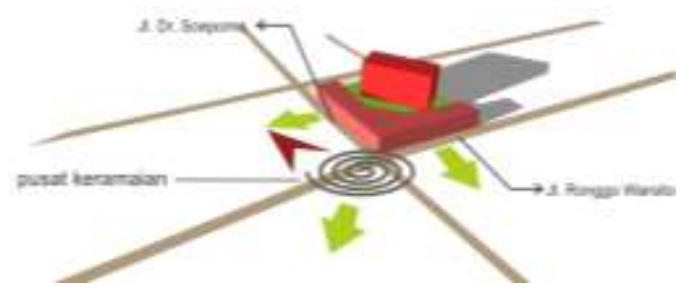

Gambar 4. Analisis Orientasi

Bangunan.

Selain pertimbangan karena faktor arah matahari, orientasi bangunan dipengaruhi oleh kesesuaian tapak dan pandangan tapak pada jalan sekitar. Pada tapak hotel resor, tapak memiliki dua muka yang dapat dilihat oleh masyarakat sekitar secara jelas, yaitu dari arah Jl. Dr. Soepomo dan dari arah Jl. Ronggo Warsito (lihat Gambar 4)

F. Analisis Pemintakatan

Pemintakatan berdasarkan sifat kegiatan dan keadaan dalam tapak dilakukan sebagai acuan dalam penataan peruangan, namun tetap memperhatikan modul-modul struktur yang telah diterapkan.

1. Tujuan: Menentukan mintakat (zoning) berdasarkan sifat kegiatan dan keadaan pada tapak.

2. Dasar pertimbangan: analisis peruangan, dan kemudahan sirkulasi.

3. Proses analisis: Pemintakatan (zoning) dibagi menjadi dua yaitu pemintakatan secara umum yang dibagi menjadi dua yaitu mintakatan publik dan mintakatan private, mengingat hotel resor tidak hanya berfungsi sebagai area penginapan namun juga sebagai penyedia ruang publik. Sedangkan, analisis pemintakatan secara khusus dibagi menjadi lima mintakatan yaitu mintakatan publik sebagai ruang publik yang dapat diakses oleh semua pengunjung resort. Mintakatan semi publik sebagai ruang publik untuk pengguna hotel resor seperti kolam renang, spa, dan fasilitas-fasilitas lain. Mintakatan servis sebagai ruang servis yang digunakan oleh pegawai hotel resor, seperti dapur, laundry, dan lain-lain. Mintakatan privat digunakan sebagai ruang hunian untuk pengunjung hotel resor yang melakukan penginapan (lihat Gambar 4).

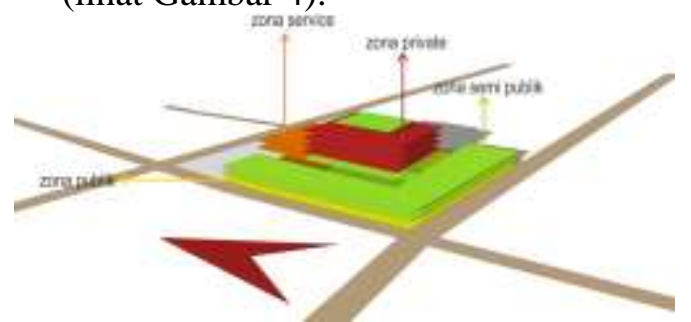

Gambar 4. Pemintakan Pada Urban Resort. 
G. Analisis Bentuk Bangunan

1. Tujuan: Mendapatkan bentuk ideal untuk bangunan Urban Resort.

2. Dasar pertimbangan: Bentuk bangunan yang dipengaruhi oleh respon bangunan terhadap iklim sebagai bentuk penerapan Ekologi Arsitektur pada bangunan, efektifitas ruang-ruang yang akan terbentuk, kemudahan dalam pengolahan sirkulasi, dan bentuk bangunan yang tipis untuk memperlancar gerak angin dalam bangunan.

3. Proses analisis: Berikut ini adalah tabel karakteristik bentuk dasar bangunan, untuk mempermudah pemilihan bentuk bangunan hotel resor.

Tabel 1. Karakteristik Bentuk Dasar

\begin{tabular}{|c|c|}
\hline $\begin{array}{l}\text { Bentuk } \\
\text { Dasar }\end{array}$ & Karakteristik \\
\hline $\begin{array}{c}\text { Segi } \\
\text { Empat }\end{array}$ & $\begin{array}{l}\text { - Karakter bentuk } \\
\text { netral, statis, formal, } \\
\text { solid } \\
\text { - Kemudahan untuk } \\
\text { pengolahan sirkulasi } \\
\text { - Efisiensi pemakaian } \\
\text { ruang dan fungsi } \\
\text { - Kemudahan dalam } \\
\text { pengerjaan struktur } \\
\text { - Kesesuaian dengan } \\
\text { bentuk tapak } \\
\text { - Mudah melakukan } \\
\text { pengembangan } \\
\text { terhadap bentuk dasar }\end{array}$ \\
\hline Lingkaran & $\begin{array}{l}\text { - Mempunyai sudut } \\
\text { pandang ke segala } \\
\text { arah tanpa dihalangi } \\
\text { pertemuan } \\
\text { - Dengan } \\
\text { pengembangan } \\
\text { bentuk akan } \\
\text { menimbulkan gerak } \\
\text { putar yang kuat, } \\
\text { dinamis } \\
\text { - Kemudahan untuk } \\
\text { pengolahan sirkulasi } \\
\text { - Membutuhkan }\end{array}$ \\
\hline
\end{tabular}

$\begin{array}{|cl|} & \text { pengolahan struktur } \\ \text { yang rumit }\end{array}$

Sumber: Ching, 2008

Berdasarkan kelebihan dan kekurangan masing-masing bentuk di atas maka dipilih bentuk persegi panjang sebagai bentuk Urban Resort.

Bentuk bangunan harusnya menyesuaikan diri dari respon terhadap pergerakan angin dan matahari. Sinar matahari pagi (dari timur) masih dapat ditoleransi karena matahari pagi baik untuk kesehatan. Sedangkan untuk mengatasi matahari sore (barat), mengusahakan bagian yang terkena sinar matahari sore sekecil mungkin. Sehingga panas dari sinar matahari tidak terlalu banyak masuk ke dalam bangunan dan kesejukan di dalam ruang tetap terjaga.

Sesuai dengan pendekatan Ekologi Arsitektur yang digunakan, bentuk bangunan baiknya mengikuti arah gerak angin. Agar ruang-ruang pada bangunan dapat menggunakan penghawaan alami dengan maksimal (lihat Gambar 5). 


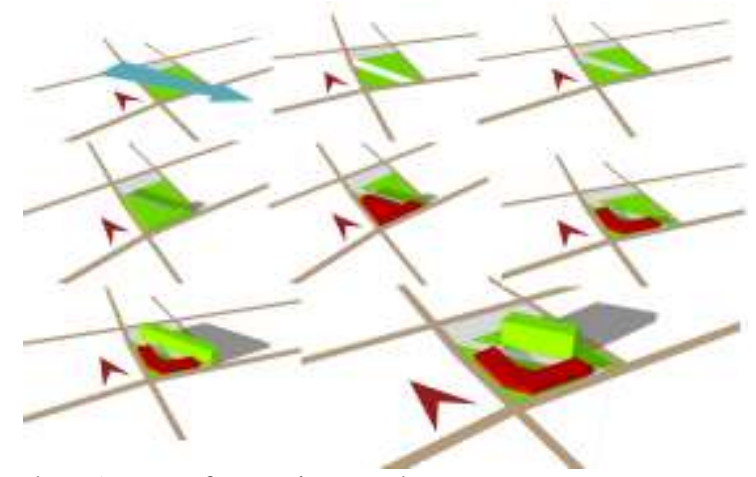

Gambar 5. Transformasi Bentuk Bangunan Resor di Tengah Kota.

F. Analisis Tampilan Bangunan

1. Tujuan: mendapatkan fasad yang estetis.

2. Dasar pertimbangan: bangunan harus mengesankan kesan ekologis dan modern.

3. Proses analisis

Penerapan tampilan ekologis dapat dilihat pada tampilan Rumah Turi Solo, dan Nanjing Eco House yang menonjolkan bukaan-bukaan dan penerapan tanaman hijau sebagai filter untuk udara yang masuk ke dalam bangunan. Selain itu Nanjing Eco House juga menerapkan kesan modern dengan mengunakan kaca sebagai tampilan bangunan dengan menggabungkannya dengan ornamen kayu agar terkesan lebih hangat.

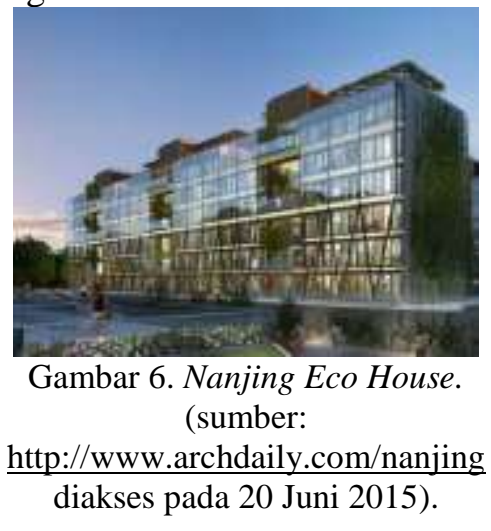

Jadi tampilan bangunan yang akan diterapkan adalah tampilan bangunan modern dengan perpaduan pengaplikasian materialmaterial alam dan tanaman. Material-material yang digunakan adalah material dengan kesan modern namun dipadukan dengan material alam yaitu kaca, batu alam, dan tumbuhan rambat. Selain itu terdapat shading pada bangunan untuk mengurangi sinar matahari langsung yang masuk ke dalam ruangan, sehingga suhu ruangruang pada bangunan tetap nyaman.

\section{G. Analisis Utilitas}

Dalam perancangan Urban Resort dengan pendekatan ekologi arsitektur, tidak hanya tampilan bangunan yang mencerminkan ekologi arsitektur, namun sistem operasional di dalamnya harus mencerminkan bangunan yang ekologis.

1. Tujuan: Menjadikan bangunan lebih hemat energi.

2. Dasar pertimbangan: penggunaan energi-energi yang dapat diperbaharui atau penggunaan energi terbarukan.

3. Proses analisis: Dengan kondisi Kota Solo yang panas dan terkena paparan sinar matahari sepanjang tahun, penggunaan panel surya dapat membantu dalam penyediaan energi di Urban Resort, sedangkan untuk penerapan konservasi air digunakan Wastewater Garden (WWG) yang mampu mengubah grey water menjadi air yang dapat dimanfaatkan kembali. Misalnya untuk air flush dan penyiraman tanaman.

\section{KESIMPULAN (KONSEP DESAIN)}

Konsep rancangan Urban Resort mengacu pada penerapan Ekologi Arsitektur yang diterapkan hampir pada setiap elemen perancangan resor hotel. Dirancang untuk mencapai kenyamanan para pengguna secara alami meskipun hotel resor terletak di tengah kota. Selain itu memberikan ruang terbuka yang cukup dan diolah dengan baik agar dapat dinikmati oleh wisatawan maupun masyarakat sekitar (lihat Gambar 12). Untuk meningkatkan keinginan wisatawan untuk tinggal lebih lama di Kota Solo, juga sebagai bentuk dukungan kepada Pemerintah Kota 
Solo untuk membentuk kota yang ekologis, ruang terbuka yang ada di hotel resor relatif banyak baik ruang terbuka yang dibuka untuk umum maupun yang hanya dapat diakses oleh pengguna hotel (lihat Gambar 8,9,11,12). Maka dari itu, respon bangunan terhadap iklim lebih dikedepankan agar bangunan mampu memberikan kenyamanan termal dan bentuk bangunan dapat meghindari sinar matahari langsung dan memaksimalkan penghawaan alami. Untuk menghindari sinar matahari secara langsung yang tidak dapat dihindari, bangunan menggunakan sun shading (lihat Gambar 10). Penghawaan alami diperoleh dari banyaknya bukaan yang ada pada bangunan (lihat Gambar 7 dan 9).

Dari hasil analisa serta hasil korelasi dari beberapa data di atas, maka diperoleh hasil berupa rancangan Stadion di Surakarta sebagai berikut.
Nama Hotel : Urban Resort
Lokasi : Jl. Ronggo Warsito
Luas Lahan $\quad: 1.600 .000 \mathrm{~m}^{2}$
Luas Bangunan : $90.000 \mathrm{~m}^{2}$
Daya Tampung : 104 kamar

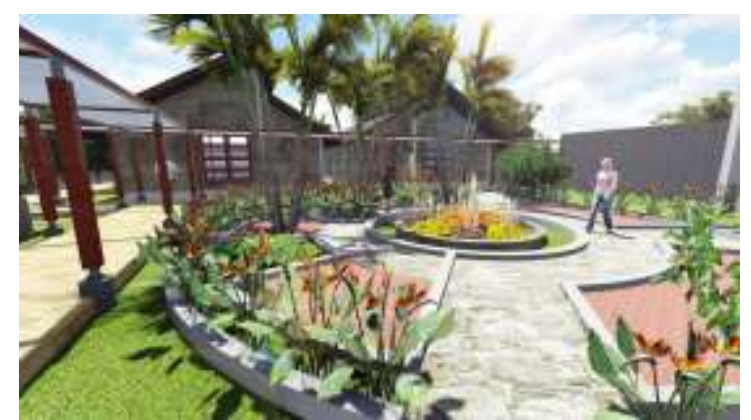

Gambar 8. Taman Dalam Hotel yang Hanya Dapat Dinikmati Oleh Pengunjung Hotel Sekaligus untuk Mencapai Pemberian 40\%RTH Dalam Tapak.

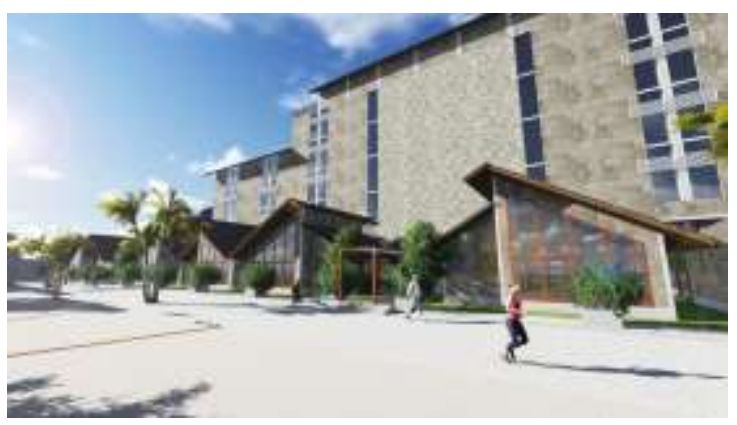

Gambar 9. Perspektif Gedung Hunian yang Menggunakan Shading.

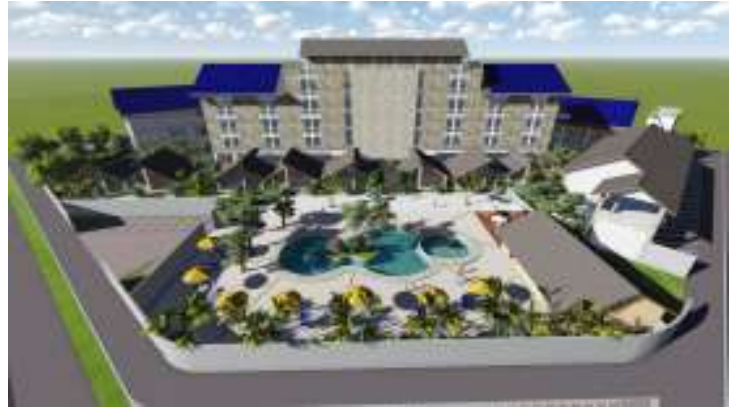

Gambar 10. Perspektif Bangunan Dari Arah Timur Tapak.

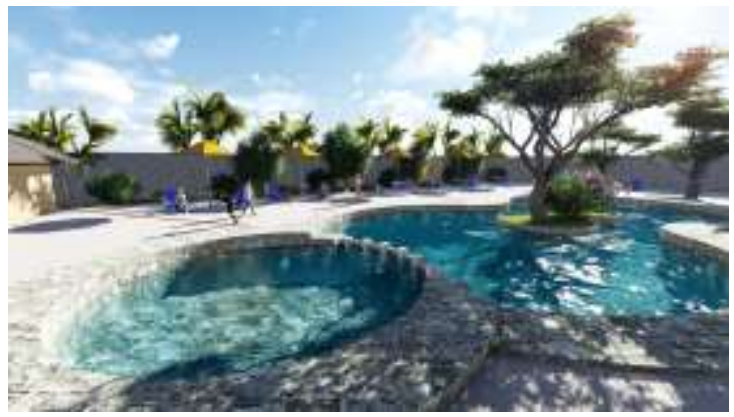

Gambar 11. Kolam Renang Urban Resort.

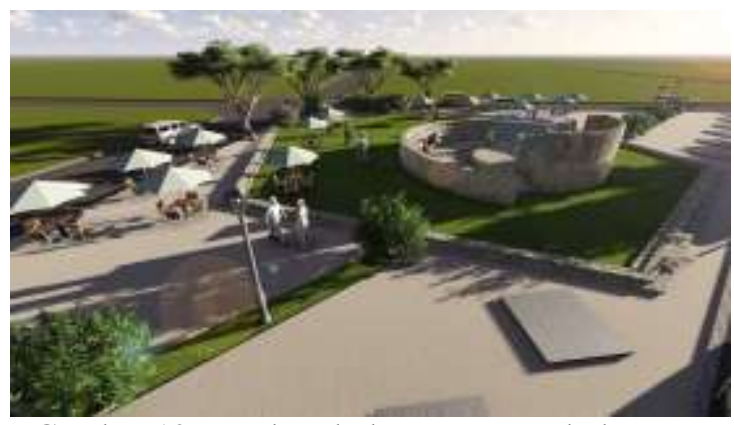

Gambar 12. Food Park dan Ruang Terbuka yang Ada Pada Urban Resort Sebagai Ruang Interaksi Antar Wisatawan dan Masyarakat.

\section{REFERENSI}

BPS Surakarta. 2012. Kota Surakarta Dalam Angka 2012. Surakarta: BPS Surakarta.

Ching, Francis D.K, 2008, Bentuk, Ruang dan Tatanan.

Heinz Frick dan Tri Hesti Mulyani, 2006. Arsitektur Ekologis, Konsep Arsitektur Ekologis di iklim tropis, penghijauan kota dan kota ekologis, serta energy terbarukan. Kanisius dan Soegijapranata University Press. Semanarang http://www.archdaily.com/nanjing yang diakses pada 20 Juni 2015. 